Sports medicine

\section{Musculoskeletal medicine/sports medicine}

\section{MacAuley}

\section{Bumps, bruises, and a research agenda}

S aturday afternoon, five o clock, and its football time in the casualty waiting room. A colourful zoo of mud splattered jerseys, with makeshift splints, slings, and sodden ice packs. In a world of trauma and triage, musculoskeletal injuries take their place at the back of the queue. Weekend warriors limping home with this month's NSAID and a double Tubigrip. And not just Saturday, for everyday brings sporting casualties with their predominantly soft tissue injuries. Hidden behind the drama of A\&E is an army of patients with non-life threatening but lifestyle threatening injuries. How do we treat them and is it evidence based?

Ask anyone and they will trot out the usual recipe of RICE meaning rest, ice, compression, and elevation. A mantra for musculoskeletal injury. Delve a little deeper and evidence becomes a little thin. Our patients often leave with verbal advice, perhaps even a leaflet suggesting RICE but how much do we really know about the effect of ice.

For how long should it be applied, how often, and for how many days? What temperature is the ice? Melting iced water will be at $0^{\circ} \mathrm{C}$, but ice taken directly from a freezer may be much cooler, and do we know the temperature of commercial ice packs? And thinking about the effect of ice-how deep does the cold penetrate and does it vary depending on the size of the limb and the thickness of subcutaneous fat? And finally, what effect does the ice have on the local tissue? Clearly our time honoured advice needs a little more focus. ${ }^{1}$ When we begin to look at the evidence base for compression, the literature is sparse. Wilson and Cooke, ${ }^{2}$ in their systematic review, suggested that optimal treatment may be to maximise movement without a bandage and advice on exercise. They questioned why we use a cylindrical bandage when the ankle has a $90^{\circ}$ curve and pointed out that, based on the incidence of sprained ankle, the annual single layer Tubigrip usage would stretch $300 \mathrm{~km}$, or $600 \mathrm{~km}$ for our classic double Tubigrip. And elevation? Is there any evidence?

Few would contest that ankle sprain is a common presentation in accident and emergency. But it is remarkable that according to Bridgman et al, we have little epidemiological data on the incidence. ${ }^{3}$ In this issue, they estimate crude incidence rate to be 52.7 (95\%CI 51.3 to 54.0) per 10000 , with an adjusted rate of 60.9 (95\%CI 59.4 to 62.4), indicating that there are 302000 ankle sprains per annum in the UK. They also present a snapshot showing considerable differences in management based on a survey of A\&E departments. Another paper in this issue studies ankle injury. Cooke and his colleagues present the results of their survey of A\&E departments showing wide variation in treatment based on a simple scenario. ${ }^{4}$

Clearly, there is a problem. We have a common injury, presenting often to A\&E, with little agreement on management, and little research evidence on which to base best practice. We need trials. But there is some flicker of hope as Cooke and his colleagues are about to embark on a large randomised controlled trial to explore the benefits of different management strategies. This is a model for the future.

Hidden in the cubicles of A\&E is an opportunity to research optimal treatment of soft tissue injury. The ankle sprain is just one example but it is humbling to think that we have so little evidence to guide treatment of such a common injury. While sports people are the most visible patients with soft tissue injury, the principles learned in treating the athlete can be applied equally to all ages and all levels of fitness. Their bumps and bruises, strains and sprains, offer a model for learning optimal treatment strategies. Different joints, limbs, contusions and abrasions. No other branch of medicine has the opportunity to explore acute musculoskeletal injury; basic principles, aids to recovery, physiotherapy, the health economic perspective. A\&E on the evidence based medicine bandwagon.

Emerg Med J 2003;20:500

\section{Author's affiliations}

D MacAuley, Department of Epidemiology and Public Health, The Queen's University of Belfast, Belfast BT9 5JS, UK.

domhnall.macauley@ntlworld.com

\section{REFERENCES}

1 MacAuley D. What is the role of lce in soft tissue injury management. In: MacAuley D, Best T, eds. Evidence based sports medicine. London: BMJ Books, 2002

2 Wilson S Cooke M. Double bandaging of sprained ankles. BMJ 1998;317:1722-3.

3 Bridgman SA, Clement D, Downing A, et al. Population based epidemiology of ankle sprains attending accident and emergency units in the West Midlands of England, and a survey of UK practice for severe ankle sprains. Emerg Med J 2003;20:508-10.

4 Cooke MW, Lamb SE, Marsh J, et al. A survey of current consultant practice of treatment of severe ankle sprains in emergency departments in the United Kingdom. Emerg Med J 2003:20:505-7. 